\title{
Study on Multi-level Rural Finance Service System with Establishment of Village or Township Banks
}

\author{
Mugeng Guo \\ Yangtzeu University College of Arts and Science \\ Jingzhou 434020, China \\ E-mail: guomghb@sohu.com
}

\begin{abstract}
The problem of rural finance is one of key and difficult questions in Chinese finance reform. With the establishment of village or township banks, the condition on shortage of fund in rural areas will be gradually relieve. However, multi-level rural finance service should be established in order to sever for the new rural reconstruction. This article analyzes that the village or township banks have an important effect on and play an active role in rural finance service system from the connotation and characteristics of the village or township banks and the characteristics of rural economy in China.
\end{abstract}

Keywords: Village or township banks, Rural finance, Rural economy

\section{Introduction}

By the People's Bank of China and the Asian Development Bank jointly organized to "improve the rural financial markets, the international workshop" was held in Beijing on 19 to 20 April 2008. Experts and scholars who are researching in the rural financial and relevant government department are responsible for more than 160 people taken part in the workshop to explore the problem of diversification of financial services in rural areas. Now, the problem of rural finance is one of key and difficult questions in Chinese finance reform.

\section{The Connotation and Characteristics of Village or Township Banks}

The village or township banks hereunder refer to the banking financial institutions set up by domestic or foreign financial institutions, domestic non-financial legal entities, and/or domestic natural persons in rural areas with the approval of the China Banking Regulatory Commission (hereinafter referred to as the "CBRC") in accordance with applicable laws and regulations, to provide financial services mainly to local farmers, agricultural production and rural economy. A village or township bank is an independent legal entity that enjoys the entire property of the entity that is formed by the investments of its shareholders. It shall fully enjoy civil rights and assume civil liabilities to the extent of all its assets. About characteristics of village or township banks, this article sums up the CBRC Guidelines on Adjusting and Relaxing Banking Financial Institutions Market Access Policy in Rural Areas to Support Socialism New Countryside Construction and Provisional Rules Governing Village or Township Banks as follows:

\subsection{Property Right Structure}

The village or township bank is a joint-stock Bank with clear and diversified ownership structure. Establishment of a village or township bank requires at least one of the initiators or contributors shall be a banking institution. The controlling shareholder or sole shareholder of a village or township bank must be a banking institution. The controlling shareholder who is a banking financial institution shall hold at least 20 per cent of the bank's total equity. The individual natural persons and their related parties shall hold no more than 10 per cent of the bank's total equity and the individual non-bank financial institutions or non-financial enterprises shall hold no more than 10 per cent of the bank's total equity. Any organization or individual who wants to hold more than 5 per cent of a village or township bank's total equity shall obtain prior consent of the CBRC local offices.

\subsection{Governance Structure}

A village or township bank different from the bank office is a primary corporation setted up by modern enterprise system. This kind of flat structure makes its decision-making chain has a quick response, innovates financial products in view of the current development for agriculture and rural economy and opens business according to the principle of marketization to form the operation flow close to the countryside. A village or township bank shall put in place a simplified and flexible organizational structure tailored to the complexity of its decision making management, business dimension as well as service features. This organizational structure shall not only improve operational efficiency of 
decision-making but also strengthen the resumption control for senior management to prevent the abuse power.

\subsection{Operation Objective}

Village or township banks shall not grant loans to those other than local borrowers. They provide financial services mainly to local farmers, agricultural production and rural economy as well as in pursuit of bank profitability, which is dicided by their sustainable development.

\subsection{Operation Characteristics}

Village or township banks have advantages of paying relational loans to rural households and small and medium-sized enterprises with opaque information through the long-term and close contact with them to get various soft information as a result of its characteristics of regional and community. In service features, village or township banks are efficient with concise formalities and quick audit abandon of multifarious procedure. Especially, they can provide targeted personalized financial services by means of accurately mastering the local market and customer information. For example, village or township banks can take loans to the fields where villagers are cultivating to make them feel convenient.

\section{The Establishment of Village or Township Banks}

On December 22, 2006, the CBRC promulgated the access policy of adjusting to relax the banking financial institutions in rural areas, with the method of "lower the threshold and strict the regulation", in the Midwest, Northeast and the cities and counties in Hainan Province and the following counties and cities region, as well as other provinces (autonomous regions and cities) country poverty-stricken counties and audited in poverty-stricken counties (collectively, "the financial access area") permit a variety of organizations and individuals to enter the rural financial market, through investment, acquisition, and new approach set up various forms of rural banking financial organizations. On March 1, 2007 from the CBRC promulgated the policy less than 3 months, a group of innovative rural financial institutions from paper into reality: Yilon Huimin villages and small town's bank in Sichuan, Jilin Dongfeng Integrity villages and small town banks, and Jilin Panshi financial Fung villages and small town banks officially opening. The opening of the same period has opened the Sichuan Yilon Huimin loan company; By Beijing Rural Commercial Bank to set up wholly-owned national inter-provincial first new-type rural financial institutions - "Hubei Xiantao village's north agribusiness bank" on the April 28th at Xiantao City, Hubei Province opened a formal listing. So many types of rural financial institutions started a pilot on this big screen.

The creativity of the village or township banks is that it does not need mortgage, and comparing with the rural credit cooperatives and other traditional financial institutions, the rural banks has a short processing time and the interests rate is relatively lower. Long before farmers are mainly loaning by rural credit cooperatives, the processing time is long and often delay the production of the best investment opportunity. According to the study, Ruifeng village or township banks will compress the time of farmers apply for a loan approval in a week or less, and the application procedures are more simple, according to information submitted by farmers (land situation, production, etc.) direct examination and approval, and the fee is always about 20-30 thousand, without ceiling, which is decided based on the peasant land actual operating conditions. For controlling the risks, ruifeng village or township banks require 5 UNPROFOR, that is, five farmers at the same time for a loan guarantee, which can also be 5 secured to each other. In addition, it also intend to work with the enterprises of acquainting grain in the farmer downstream and the upper reaches of the provision of seed fertilizer units, who provide guarantees, both security forces without physical collateral.

The first official introduction of competition in the banking sector in rural areas, which laid the foundation system of diversified financial organization for the banking sector in rural areas. Before it, the centralized top-down reform does not give the China's rural financial prosperity, the four state-owned banks merge institutions and authority on land, expansion of postal savings deposits and capital outflows, the system of rural credit cooperatives twist and poor management, the vast rural areas not only face their own plight of ischemia, but also a steady flow through the formal financial transfusion to the city.

However, writer thinks that the villages and small banks couldn't solve the all problems of the rural finance. As the largely unbalance of the development of rural economy in our country, which decide the diversity of finance forming, so reforming must adjust to the characteristic of rural economy.

\section{The Current Predicament of Rural Finance and Contributing Factors}

The problems currently faced by rural finance in China are the existence of serious financial constraints. These financial constraints are mainly centered on the official rural financial sector, with both shortage in thesupply of funds and insufficient demand for funds in this sector. However, the main issue is supply-relatedconstraints while that related to demand is less important.

\subsection{The supply-related and demand-related constrains on rural finance}

Currently, supply-related finance constraints in Chinese rural finance mainly reside in the insufficientnetwork of official 
financial institutions and in an insufficient supply of funds by these institutions.

The first is that the network of rural financial institution is inadequate. At present, although nominally their situations providing financial services to the countryside include the ABC, the ADBC, RCCs, rural Post Office Savings and the PICC, those institutions which can in fact supply funds to the countryside are very limited. The ADBC acts as a policy bank and does not provide any loan to ordinary enterprises involved in agriculture orpeasant households. Rural Post Office Savings organizations only provide a savings service but no loans. Although the ABC provides loans for agriculture, most of which are for basic rural facilities and agricultural product processing companies, with few loan for peasant households. Moreover, after the withdrawal from the rural financial network over recent years by the Industrial and Commercial Bank, the Construction Bank and the Bank of China, the ABC has not filled the gap. Therefore, millions of peasant households and tens of thousands of rural enterprises can only apply for loans from RCCs. However, only about 40000 or RCCs are legal entities and they do not form a financial network. It can be seen that there is a lack of financial institutions which can provide credit services, which is one of causes for the insufficiency in the supply of rural fund.

The second is the defects in rural financial system. Macroscopically, the mechanism of access, regulation, and withdrawal of rural financial market have not been well established, resulting in monopolization and, herein, lack of competition on rural financial market. Microscopically, the ownership of rural financial institutions is not clarified, weakening the stimulating mechanism and restricting mechanism in management, and leading to the disconnection of responsibility with profits, which have directly negative impact on the operational behavior of financial institutions.

The third is the defects in rural financial management system. Under the leadership of the United Provincial Credit Cooperatives, rural credit cooperatives that used to scatter in countryside come into factual monopolization, which meets the demand for local economic and financial development. At present, United Provincial Credit Cooperatives basically follow the model prior to the reform in distributing administrative authority and responsibility among its subordinate credit cooperatives, while the power for decision-making in allocating creditsis more centralized than before.

\subsection{The demand-related constrains on rural finance}

The insufficient effective demand by peasant households for services offered by official financial institutions leads to the demand-related financial constraints. Currently, there is an insufficient demand for financing by peasant households. On one hand, there is insufficient natural demand which is mainly determined by the low degree of rural commercialization, high farmer self-consumption of grain, oil, meat and vegetables and a limited degree of monetization which have reduced the commercial demand by peasant households for funds. On the other hand, stimulation of demand is insufficient and this is the main cause of demand-related financial constraints. In turn, this is the result of policy limiting the development of rural finance institutions.

Firstly, as the provision of consumer credit services by official institutions is lagging, the demand by peasant households for such credit is weak. Currently, it is difficult to activate the rural market in this respect, partly due to low peasants' income. However, when peasants build houses, buy durable consumer goods, educate their children, or hold weddings or funerals, it is generally difficult for them to obtain loans from official financial institutions. This forces peasants to transfer the demand for consumer credit to unofficial financial institutions and, as a result, the demand for funds from official financial institutions is reduced.

Secondly, risks in agriculture and the low degree of rural mercerization have reduced investment demand by peasant households. As natural disasters frequently occur in China and farm produce is perishable, the natural risks in agricultural production are high. But agricultural insurance is backward. At the same time, because of the low degree of market development, the risks and costs for obtaining information and technology, as well as market transactions costs, are high for peasant households. Due to such risks and a lack of correlative policy tools, the majority of peasant households can only choose to operate within traditional industries instead of entering into other businesses, other than agriculture. This restricts their channels for investment and reduces their demand for borrowing capital from official financial institutions.

Thirdly, loans from official financial institutions are difficult to access which inhibits demand for investment by peasant households. Investment loans from official financial institutions such as RCCs and the ABC are difficult for peasant households, mainly because of the lack of collateral (for example, land use rights cannot be mortgaged), guarantees are difficult and formalities complex. Striking examples of this are the difficulties of obtaining loans by impoverished peasant families or by peasants living in backward areas, as well as by households with medium or high incomes for expanding their scale of production or adjusting their agricultural structure. Since the ABC has been transformed into a state-owned commercial bank, fewer and fewer loans have been extended to peasant households. The RCCs, the main official financial institution issuing loans to peasant households, find it difficult to meet the requirements of the majority who want loans. 


\section{The Characteristic of the Recently Rural Economy in China}

After nearly 30 years of reform and opening up, China's rural economy has changed dramatically, mainly in rural areas the way of economy development has taken a big change .One is that with the developed areas of rural urbanization, which is totally integrated into the local economy at city economy, two is that parts of the developed and the central regions of the industrialization of agriculture, three are the central and western regions have substantial competitive labor output while retaining a small amount of necessary labor force engaged in agriculture at home, four are in poverty-stricken areas the traditional agriculture maintain the simple reproduction . In other words, under a condition of completely divided of the rural economic development mode, to take exactly the same mode of rural finance or system can no longer fit the current needs of rural economic development. Therefore, China's rural financial reform and positioning functions have to fit the status of the rural economy, and to adopt a different mode of development of rural finance. In china's rural areas the level of economic development different and financing needs of a wide range of diversity, it required the modernization of financial organizations and financing methods (such as agricultural enterprises demutualization, listing and financing) also have simple or even the existence of traditional financing side space. For many farmers are familiar with each other and the relatively easy credit or even the traditional credit form have the benefit of saving transaction costs. With their low-level and incompatible with the development of modern financial as an excuse to exclusive them is wrong.

China's rural financial development, we can not hope that a financial institution, nor are the local field of repair, but should be based on China's economic development stage, to serve the construction of new rural financial needs, focus on the rural economy can be sustainable development, reconstruction of a full-featured, running efficiently, multi-layered new rural financial system.

\section{Establish a Multi-Level Rural Financial Service System}

6.1 In accordance with the functional expansion of the direction of the reform of the Agricultural Development Bank to expand the scope of business and service areas, enhance the service function of agriculture. Agricultural Development Bank should make the existing grain industry leading enterprise loans extended to agriculture, forestry, animal husbandry, fisheries within the scope of industrialization leading enterprises. Around the use of the loans in agriculture, forestry, animal husbandry, and fishery products plant (culture), circulation, or for processing, transformation, including working capital and technological transformation, storage and other agricultural infrastructure construction and production, processing base construction and long-term credit funds required .

6.2 Definite the reform direction of the Agricultural Bank of China. Agricultural Bank of China the reform of commercial and should not be in accordance with other state-owned commercial banks to implement the reform model, and should take into account the Agricultural Bank as a "three rural" service specific features, developed to meet the concrete practice of China's reform model. As we all know, because of inefficient agriculture industry and the property's agricultural credit decide the high-risk, low efficiency, is bound to make agricultural credit business and the Agricultural Bank of contradictory nature of commercial banks, so that the Agricultural Bank will focus more and more moved the risk of small, high-yielding of non-financial sector . Should further clarify the direction of the Agricultural Bank reform, the reform should be limited commercialization. Concrete can take the following measures: First, clear the Agricultural Bank as a "three rural" services, so that the Agricultural Bank of mainly rural areas, provision of agricultural loans, rural credit cooperatives and rural finance, together take up the important task of building and promoting a virtuous circle of rural capital. Two are in order to increase support for rural finance, revenue at the bank to give more concessions in agriculture to reduce its rate of sales tax and to reduce the operating costs of the Agricultural Bank. Three are central banks give the Agricultural Bank more preferential refinancing to solve the shortage of funds of the Agricultural Bank and Agricultural Bank lending rates greater space to float in order to improve efficiency in the use of credit fund.

6.3 Continue to deepen reform of rural credit cooperatives, support for the development of cooperative financial organization. About reform of rural credit cooperatives, we have explicitly at the structure of property rights can be taken on stock, stock cooperative system and the cooperative system in three ways, in the organizational model can be set up on commercial banks, cooperative banks and cooperatives in three forms of organization. All localities are required to select suitable conditions reform pattern, in general, the economically developed areas should be put stock and shares co-production models for major reform, the economy in underdeveloped regions should be based on joint-stock cooperative system and the co-production as the main mode of selection, while the poverty-stricken areas credit cooperatives reform and policy direction should be dominated cooperative system. However, regardless of what system of property rights and forms of organization, must be in accordance with the shareholding structure of diversification and the principle of investment diversification, and improve their corporate governance structures at concentrated efforts on a sound set up credit cooperatives operating incentive and restraint mechanisms, and enhance service rural economic development initiative. At the same time, some are willing to stick to the road of rural credit cooperatives financial cooperation, it is necessary to take measures to become members to become shareholders, democratic management, and services mainly for members of the really rural cooperative financial organizations and 
foreign cooperation in the financial experience, through the free levy of interest tax, business tax and income tax relief, less deposit reserve mentioned in the loan than keeping the right amount of give another way to carry out the necessary loans and other support.

6.4 Set up a comprehensive agricultural insurance system. This can enhance agriculture's ability to resist risks, improve the repayment ability of farmers, thereby reducing the loan risk, increasing their loans enthusiasm, the elimination of the lending bank's worries for the future. According to the reality of our country, at present, it is necessary to set up the policy of Chinese characteristics, agricultural insurance system, that is, to set up under the government-led policy-oriented insurance system model. The so-called policy is to regard agriculture insurance products as a quasi-public goods rather than personal belongings, adopting the form of commercial insurance and technology operation. The so-called government-led, that is, the government should provide a unified system framework for insurance of agriculture operated politically. All levels of government and a variety of organizations permitted should operate insurance and reinsurance in the framework. At the same time, the provisions of financial support are given by the government to the agricultural insurance product. So recommend the establishment of professional part of the Central Government or a department of the Chinese agricultural insurance companies, the companies operating the country's rural insurance business. The government, the insurance industry, farmers and financial institutions benefit from the establishment of professional Chinese agricultural insurance company. Agricultural insurance can significantly reduce the risk of loans of financial institutions coefficient, Farmer's default risk is also greatly reduced, so that rural financial institutions, "credit crunch" of the situation will be alleviated on a large extent.

6.5 Guide and open rural folk financing. Private finance is to ensure the stability of local economic development agents and the catalysts. China's formal finance is significantly affected by the state- controlled tradition .It is a top-down strategy of credit. Credit is controlled by a number of ministries and department director of financial control; we call it a "first supply" type, more susceptible to national macro-control policy intervention, not in conformity with the laws of economic operation. In addition, the internal control problem, the formal financial members are often unable to represent the shareholders interests. Private Finance is different, it is "needs follow-up" type, there is what kind of market demand will have what kind of supply, and it is very scattered, it is precisely in line with the small amount of money farmers scattered required. Rural folk have many financial forms, they scattered in small and medium-sized farmers and the provision of financial services has a natural advantage: First, based on popularity, blood and fate industry relations of mutual trust and understanding, as well as social exclusion of informal sanctions mechanisms, such as gossip. With these social network, information obtained is the most full and most symmetrical. Second, loans are simple, in general it do not need collateral, guarantee, pledge and so on. If you need to mortgage or pledge, you can receive some goods which formal lenders are unacceptable, non-standardization of mortgage and pledge of goods, such as land tenure security, labor security, there is no evidence of real estate mortgage, the fields are not harvested, such as Young mortgages. Third, loans are generally concentrated in a fixed narrow geographical range, a relatively fixed group of clients, many borrowers are assumed to unlimited liability. Fourth, both lenders and borrowers usually at the same time maintain a working relationship, the relationship between business transactions and financial transactions relations, inextricably linked to make credit transactions more easily to set up, such informal credit transactions depend on the conditions at other markets on terms of trade, credit minimal risk. China's rural financial reform and control is necessary to change the country's traditional thinking, planning and centralization of power because only a small number of people to take care of preferences will not solve the problem of asymmetric information. Market is not, small businesses and a lot of small farmers, their demand is totally different, it may be policy-makers formulate policy in the first did not understand. Therefore, what the policy-makers need to do is to rule out a small part might lead to bad results, other may let financial between civil, civil financial and between the formal financial freely compete. When the market supply side is particular perfect, each person will be in the best approach to financing, so market interest rates will reach equilibrium, but the interest rates is otherwise not high. In contrast, if the market does not open, privilege will play a role, corruption will breed.

\section{The Village or Township Banks Playing an Active Role in Rural Finance Service System}

It is important significance for forming an multi-layered and emulous rural financial market to establish village or township banks. It is an useful attempt to solve the problem of low network coverage of financial institutions due to undersupply and ease the shortage of funds. However, we also hard to predict and confirm their negative impact on rural finance due to short experimental time and inadequate empirical data. As things stand, village or township banks play an positive role in rural finance in china.

\subsection{Favoring the formation of multi-level and competitive financial markets in rural areas}

Theoretical and regulatory circles generally form such a consensus, that is to say, to set up a multi-level financial service system for rural financial reform ideas. However, rural finance belongs to small profits finance compared with other forms of finance. The most financial subjects are reluctant to participate in rural finance for a long time, which make the reform on rural finance always revolve around the rural credit cooperatives. The rural credit cooperatives in a 
monopoly in rural finance. Although China make reform attempts for the rural credit cooperatives many times, the rural financial reform started late, progress is slow and there are still some profound contradictions and problems relative to the city finance owing to a variety of reasons. Now, these problems have become "bottleneck" restricting the development of rural economy that the network coverage of financial institutions in the banking industry is low, financial supply is not enough and competition is inadequate. The monopoly situation of the existing rural credit cooperatives is broken and the new subject is increased so as to aggravate competition in rural financial market in a certain extent through the establishment of village or township banks.

\subsection{Relieving the diminution of the rural financial resources}

The characteristics of agricultural "vulnerability" restricts the development of the rural finance. Its outstanding performance are the lack of financial resources and the phenomenon of fund outflow of rural financial market by state-owned commercial Banks and the postal savings. This situation is relieved effectively after four state-owned commercial banks withdraw their branch offices in the county towns and postal savings maked postal savings bank. However, the rural credit cooperatives will remain strong wish for commencing business in the town. Each year they still transfer part of agricultural deposits to the city in disguised form, which leads to the development of rural economy by capital "bottleneck" limitation. The author estimates through measuring that capital outflow of the rural areas by the rural credit cooperatives is about 40 million yuan, 14.4 percent of total absorption deposits of rural credit cooperatives, across the country in 2005. From this, it can be seen that the phenomenon of fund outflow is very serious. The village or township banks can relieve rural financial resources in a certain extent.

\subsection{Forming the substitute for the private finance}

The state-owned commercial banks gradually withdraw the rural financial markets from the angle of financial institutions in recent years, resulting in the rural credit cooperatives dominant in rural finance. Owing to the scarcity of financial institutions and the shortage of normal development channels, large numbers of civilian capitals participate in various forms of underground financial activities with various "grey" status, which disturbs the country's financial order to a certain extent and gives capital owners bring huge financial risks. The village or township banks can form the substitute for the private finance in a certain extent. First, The relevant provisions of the establishment of the village or township banks makes it clear that a domestic natural person can take shares in a village or township bank, which is very attractive to long-term discriminated folk capitals in formal finance. It is reported that many merchants in zhejiang province value village or township banks and Some of them have submitted the relevant application plans for the establishment of the village or township banks after the village or township banks are pilotted in selected provinces and cities. Second, the village or township banks expand the formal financial institutions in the rural areas and can bring a certain proportion of private financial resources into the formal financial system under the premise of constant total financial resources.

\section{Conclusions}

Return on investment in the village or township banks as new rural financial institutions is very considerable in the conditions of starved financial needs and insufficient financial supply in the vast rural areas. The village or township banks are springing up all over the nation in the norms of national policy and market commercial interests drive. The author believes that the village or township banks in China will play an more and more important role in the rural economy with the continuous improvement of the rural financial system and the steady development of agricultural economy.

\section{References}

Huang Qinghua. (2008). The Theoretical Principle on the Establishment of the Village or Township Banks and the Definition of Related Concept. Journals of Fujian Business Higher Junior College. (8): P32-35

Wang Liang, Lei Li-jun. (2008) Analysis on the Effect Establishment of the Village or Township Banks on the Rural Finance in China. Journal of Inner Mongolia Financial Research. (7): P21-25.

Xie Qi-biao. (2007). International experience and countermeasure of Rural financial development. Journal of the XiaMen Special Economic Zone Party. (1): 39-42.

Zhang Liang. (2007). On the problem of farmers' difficult to loan in our country. Economic Research Guide, (2):53-54.

Zhang Yuwen. (2005). The research on the question of China's rural financial development. Beijing: Economic Science Press.

Zhou Xiaochuan. (2004). About the points of rural financial reform ideas. Dynamic Economics, (8): 10 - 14. 